\title{
A SUSTAINABILITY INDEX FOR THE EVALUATION OF MACHINING OPERATIONS
}

\author{
ToledAnO, C. \& DOMINGO, R.
}

Abstract: The manufacturing plants have carried out efforts towards a greater environmental commitment. Many variables involve in the manufacturing processes, as the machining, and for this reason to know the contribution of these variables can contribute to get better practices. The present work exposes an index of integrated sustainability for the evaluation of the machining operations, in particular in the drilling. This index considers energy aspects of the process, as well as the surface quality of the part and the life of the cutting tool, and allow the optimization through of an interaction algorithm, based on the process cut-off parameters. The theoretical development has been contrasted with experimental data. The cutting parameters obtained from the sustainability index, does not correspond to the most economic option or the fastest, but allows that all the variables of the study simultaneously (roughness, time, cost, tool life and energy) obtain a better commitment.

Key words: Sustainability, green manufacturing, machining, drilling, index
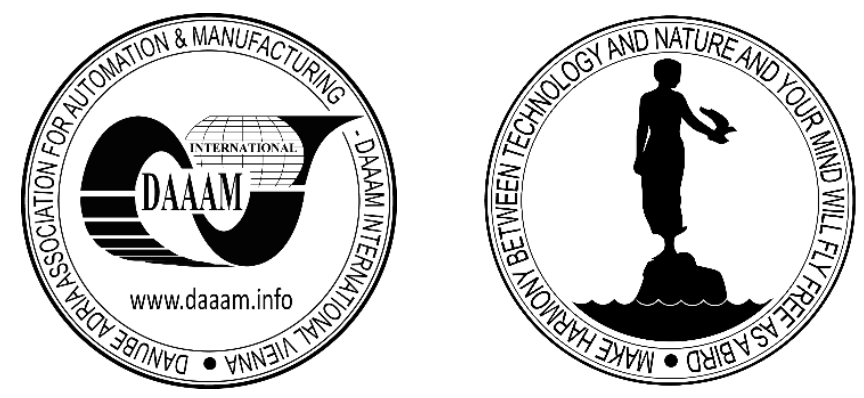

Authors' data: Master-Ing. Toledano, C[laudio]*; Full Professor Domingo, R[osario]**, Universidad Nacional de Educación a Distancia (UNED), Department of Construction and Manufacturing Engineering, Calle Juan del Rosal 12, 28040, Madrid, Spain, claudiotoledano@gmail.com*,rdomingo@ind.uned.es**

This Publication has to be referred as: Toledano, C[laudio] \& Domingo, R[osario] (2018). A Sustainability Index for the Evaluation of Machining Operations, Chapter 23 in DAAAM International Scientific Book 2018, pp.265-272, B. Katalinic (Ed.), Published by DAAAM International, ISBN 978-3-902734-19-8, ISSN 1726-9687, Vienna, Austria

DOI: $10.2507 /$ daaam.scibook.2018.23 
Toledano, C. \& Domingo, R.: A Sustainability Index for the Evaluation of Machini...

\section{Introduction}

The introduction of environmentally friendly practices in manufacturing plants is an important challenge that the industry has recently faced; environmental innovation has been managed to improve performance and sustainability indicators (Aguado et al., 2013) and the control of process parameters allows for significant reductions in terms of energy and $\mathrm{CO}_{2}$ emissions (Calvo \& Domingo, 2015). This is extensive to processes, products (Kralikova et al., 2017) and projects (Majstorovic et al., 2016). Some models or indexes have been developed integrating sustainability and efficiency, integrating general and specific criteria to achieve a green production (Tsai et al., 2015), or as Rehar et al. (2017) that study the influence of the parameters on the product lifecycle or considering the level of manufacturing facility (Domingo \& Aguado, 2015), but it recommendable to set indexes that allow taking account the particular characteristics of each manufacturing process as the machining.

Machining processes are the most used in the industry because of its great versatility and in particular the drilling processes are one of the most important because they are part of the operations prior to the assembly of numerous parts. Therefore, the advances in terms of sustainability in these processes are of great interest. In recent years, significant advances have been made in this regard, for example looking for models to optimize ecological, economic and technological objectives (Hassine et al., 2015), and in a more particular manner, analyzing the influence of cutting inserts on power consumption and emission generation (Domingo et al., 2015) or analyzing alternative procedures, reducing the temperature during the process (Tazehkandi et al., 2016) or even with temperatures below zero degrees (Domingo et al., 2018a); in fact Debnath et al. (2014) identify some techniques for cooling the tools during the process as a step to achieve cleaner production.

The academic literature shows that the surface quality affect to efficiency and sustainability because can determine the number of operations required; for this reason the roughness is a very studied variable, in particular its predictions through of the knowledge of some variables as chip size (Zuperl \& Cus, 2015) or the influence of cutting parameters on different operations as milling (Qehaja et al., 2016) or drilling [Domingo et al., 2013). The tool life affects to surface quality (Kumar, 2017), therefore it is other element to consider, and moreover affect clearly to sustainability due to the material wear and to the machining time due to tool change; it is clear that to higher tool wear, the change time will higher.

In consequence, the machining time is other influence factor; it is conditioned by the cutting conditions (Saric et al., 2016 ) and the equilibrium between efficiency and sustainability should be found by an equilibrium between machining time and energy consumption through of the lowest cutting forces (Alvarez et al., 2011) and the lowest torques (Domingo et al., 2018b) because allow a lowest energy (Domingo et al., 2013b), and finally this affects directly on the cost.

Therefore, this work presents an index to define the sustainability in the machining, and in particular in the drilling, considering the cost, the energy, the time, the tool life and the roughness. 


\section{Methodology}

\subsection{Sustainability Index}

As a result, two sustainability indexes have been defined, one considering the cost (C) and another without it. In addition, the variables consumed energy (E), cutting times $(\mathrm{t})$, tool life (Tl) and surface roughness (Ra) were taken into account.

$$
I_{S}=\sum_{i} a_{i} \eta_{i}=a_{0} \eta_{E}+a_{1} \eta_{T}+a_{2} \eta_{V}+a_{3} \eta_{R}+a_{4} \eta_{C}
$$

The variables $\eta_{i}$ represent the optimal value of the variable divided by the initial value of the variable in particular at the beginning of the iterative process. The coefficients $a_{i}$ are the weighting coefficients of each term.

$$
\begin{aligned}
& I_{s}=\sum_{i} a_{i} \eta_{i}=a_{0} \frac{E_{o p t}}{E_{\text {initial }}}+a_{1} \frac{t_{\text {opt }}}{t_{\text {initial }}}+a_{2} \frac{T l_{\text {opt }}}{T l_{\text {initial }}}+a_{3} \frac{R a_{\text {opt }}}{R a_{\text {initial }}}+ \\
& a_{4} \frac{C_{\text {opt }}}{C_{\text {initial }}}
\end{aligned}
$$

The roughness is calculated considering the following quadratic expression (Domingo et al., 2013a),

$$
\begin{aligned}
& R_{a}=2.0169-0.1200 \times V_{c}+1.3027 \times f_{d}+0.0013 \times V_{c} \times f_{d}+ \\
& 0.0675 \times V_{c}^{2}+0.2306 \times f_{d}^{2}
\end{aligned}
$$

This expression has been taken because the roughness is related with the delamination factor $(f d)$, which it importan to determine the hole quality.

The tool life is calculated by means of the equation of Taylor,

$$
C=V_{c} \times T_{l}^{n} \times f^{m}
$$

Where, $C, n$ and $m$ are constants.

The energy consumed by the machine is calculated through the expression,

$$
E=\left(T_{o} \times N \times t_{m}\right) / 0.9
$$

Where, $T o$ is the torque, $N$ es the rotational speed and $t m$ is the machining time. This expression has been considered to taken account the machine performance, in particular 90\%, a common percentage in machine tools (Kalpakjian \& Schmid, 2013).

The total time is is the sum of the machining time $(\mathrm{tm})$ plus the tool change time,

$$
t_{m}=(l \times N) / v_{f}
$$


Toledano, C. \& Domingo, R.: A Sustainability Index for the Evaluation of Machini...

Where $l$ is the drilling lenght, while the tool change time is calculated,

$$
t_{t c}=\left(0.75 \times t_{m}\right) / T_{l}
$$

Finally, the tools, labour and energetic costs are considered.

\subsection{Experimental Procedure}

The experimental tests were carried out on plates of PEEK-GF30 with thickness of 6.3 $\mathrm{mm}$ in a machining center CNC Tongai TWV-510 and with bits of cobalt and tungsten carbide, and point angle of $90^{\circ}$. A dynamometer Kistler was connected to machining center to take data from torques and to calculate the energy.

Moreover, a rugosimeter Mitutoyo type SJ-400 was used to measure the surface quality in the holes obtained, and the perfilometer TesaVisio was used in the analysis of wear of the bits according to criteria of ISO 3685 (1993).

\section{Results}

The theorical and experimental results obtained have shown in Table 1. In general, the roughness has high differences between theorical and experimental values.

The tool life is estimated appropriately due to the Taylor equation; the highest differences appear in the test carried out to $7000 \mathrm{rpm}$. Respect to the energy, in general, the experimental vales are lower than the theoretical calculus (note that the length of the bit is conditioned by the point angle, $90^{\circ}$ in this case).

\begin{tabular}{|c|c|c|c|c|c|c|c|c|}
\hline Test & $\mathbf{N}[\mathbf{r p m}]$ & $\begin{array}{c}\mathbf{F} \\
{[\mathbf{m m} / \mathbf{m i n}]}\end{array}$ & $\begin{array}{c}\text { Ra, exp } \\
{[\boldsymbol{\mu m}]}\end{array}$ & $\begin{array}{c}\text { Ra, the } \\
{[\boldsymbol{\mu m}]}\end{array}$ & $\begin{array}{c}\text { Tl, exp } \\
{[\mathbf{m i n}]}\end{array}$ & $\begin{array}{c}\text { Tl, the } \\
{[\mathbf{m i n}]}\end{array}$ & $\begin{array}{c}\mathbf{E}, \mathbf{e x p} \\
{[\mathbf{J}]}\end{array}$ & $\begin{array}{c}\text { E, the } \\
{[\mathbf{J}]}\end{array}$ \\
\hline 1 & 6000 & 300 & 0.70 & 0.81 & 25.3 & 25.27 & 241.61 & 350.34 \\
\hline 2 & 6000 & 400 & 0.65 & 0.26 & 13.0 & 12.99 & 166.87 & 350.34 \\
\hline 3 & 6000 & 500 & 0.67 & 0.89 & 8.2 & 7.75 & 227.52 & 350.34 \\
\hline 4 & 7000 & 300 & 2.18 & 1.15 & 17.4 & 15.78 & 407.43 & 350.34 \\
\hline 5 & 7000 & 400 & 0.92 & 0.92 & 5.9 & 8.11 & 244.13 & 350.34 \\
\hline 6 & 7000 & 500 & 0.60 & 1.87 & 4.0 & 4.84 & 298.79 & 350.34 \\
\hline 7 & 8000 & 300 & 2.06 & 2.33 & 10.3 & 10.50 & 131.19 & 350.34 \\
\hline 8 & 8000 & 400 & 1.09 & 2.42 & 5.4 & 5.40 & 444.9 & 350.34 \\
\hline 9 & 8000 & 500 & 5.46 & 3.69 & 3.1 & 3.22 & 174.82 & 350.34 \\
\hline
\end{tabular}

Tab. 1. Theorical-experimental results obtained.

The values obtained for times can be seen in Table 2. It is clear that the cutting conditions affect in them, and higher speed provide lower times.

Therefore, it is important to carry out an analysis of cost. 


\begin{tabular}{|c|c|c|c|c|c|}
\hline No. test & $\mathbf{N}[\mathbf{r p m}]$ & $\mathbf{F}[\mathbf{m m} / \mathbf{m i n}]$ & $\mathbf{t m}[\mathbf{m i n}]$ & $\mathbf{t t c}[\mathbf{m i n}]$ & Total [min] \\
\hline 1 & 6000 & 300 & 84.33 & 2.50 & 86.84 \\
\hline 2 & 6000 & 400 & 63.25 & 3.65 & 66.90 \\
\hline 3 & 6000 & 500 & 50.60 & 4.90 & 55.50 \\
\hline 4 & 7000 & 300 & 84.33 & 4.01 & 88.34 \\
\hline 5 & 7000 & 400 & 63.25 & 5.85 & 69.10 \\
\hline 6 & 7000 & 500 & 50.60 & 7.84 & 58.44 \\
\hline 7 & 8000 & 300 & 84.33 & 6.02 & 90.36 \\
\hline 8 & 8000 & 400 & 63.25 & 8.79 & 72.04 \\
\hline 9 & 8000 & 500 & 50.60 & 11.79 & 62.39 \\
\hline
\end{tabular}

Tab. 2. Values of times.

Table 3 shows the values obtained for the costs, energy cost, tool cost, labour cost and total costs. With the previous hypothesis considered, a tool with a large life could reduce the cost due to this type of variable affects on a major percentage.

\begin{tabular}{|c|c|c|c|c|c|c|}
\hline No. test & $\mathbf{N}[\mathbf{r p m}]$ & $\mathbf{F}[\mathbf{m m} / \mathbf{m i n}]$ & $\begin{array}{c}\mathbf{C}_{\text {energy }} \\
{[\boldsymbol{\epsilon}]}\end{array}$ & $\begin{array}{c}\mathbf{C}_{\text {tool }} \\
{[\boldsymbol{\epsilon}]}\end{array}$ & $\begin{array}{c}\mathbf{C}_{\text {labour }} \\
{[\boldsymbol{\epsilon}]}\end{array}$ & $\begin{array}{c}\text { Total } \\
{[\boldsymbol{\epsilon}]}\end{array}$ \\
\hline 1 & 6000 & 300 & 0.04 & 690.76 & 36.18 & 726.98 \\
\hline 2 & 6000 & 400 & 0.04 & 1008.08 & 27.88 & 1036.00 \\
\hline 3 & 6000 & 500 & 0.04 & 1351.57 & 23.12 & 1374.73 \\
\hline 4 & 7000 & 300 & 0.04 & 1106.01 & 36.81 & 1142.86 \\
\hline 5 & 7000 & 400 & 0.04 & 1614.10 & 28.79 & 1642.93 \\
\hline 6 & 7000 & 500 & 0.04 & 2164.07 & 24.35 & 2188.46 \\
\hline 7 & 8000 & 300 & 0.04 & 1662.83 & 37.65 & 1700.52 \\
\hline 8 & 8000 & 400 & 0.04 & 2426.72 & 30.02 & 2456.78 \\
\hline 9 & 8000 & 500 & 0.04 & 3253.57 & 26.00 & 3279.60 \\
\hline
\end{tabular}

Tab. 3. Values of costs.

The sustainability index is represented in Table 4. According to model defined, a lower index is recommendable, in the optimization of times (optimum A) or in the optimization of costs (optimum B).

\begin{tabular}{|c|c|c|c|c|c|c|c|c|}
\hline & $\begin{array}{c}\mathbf{N} \\
{[\mathbf{r p m}]}\end{array}$ & $\mathbf{F}[\mathbf{m m} / \mathbf{m i n}]$ & $\mathbf{I}$ & $\mathbf{E}[\mathbf{J}]$ & $\mathbf{t}_{\text {tal }}$ & $\mathbf{T l}[\mathbf{m i n}]$ & $\begin{array}{c}\mathbf{R a} \\
{[\boldsymbol{\mu m}]}\end{array}$ & $\mathbf{C}_{\text {total }}$ \\
\hline Initial & 4042 & 202 & 4 & 350.34 & 125.6 & 210.61 & 4.89 & 175.4 \\
\hline Optimum A & 1400 & 504 & 3.22 & 350.34 & 50.66 & 659.6 & 7.31 & 37.03 \\
\hline Initial & 4042 & 202 & 5 & 350.34 & 125.6 & 210.61 & 4.89 & 175.4 \\
\hline Optimum B & 1100 & 539 & 3.41 & 350.34 & 46.88 & 1152.82 & 8.31 & 27.98 \\
\hline
\end{tabular}

Tab. 4. Sustainability Index (Is).

As is seen, high feed rate provide a good sustainability index and besides, in this case, the tool life is longer (three or six times higher). 
However, the rotational speed should be determined with minor values. These values are coherent with lower times and costs and a lower roughness, finding an equilibrium between the different variables studied.

\section{Conclusion}

A way of evaluating the degree of sustainability of composite materials through a Sustainability Index has been presented and also the algorithm that allows optimizing it. The sustainability index linked to the working algorithm has allowed for each tool to find the optimum drilling conditions, considering the limitations and observations indicated in the work. The results obtained have been satisfactory and show the sustainability index as a possible criterion to evaluate the sustainability of the drilling of composite materials.

The tool and the parameters of cut obtained as the apt from the Sustainability Index, does not correspond to the most economic option or the fastest, but the one that allows all the variables of the study together (roughness, time, cost), tool life and energy) obtain a better commitment (lower sustainability index).

The optimization algorithm has an ease implementation; based on the process cutoff parameters and a few data, the actual behavior can be reproduced.

In this first approach, limitations, improvements and observations have also been found about which work should continue:

Lack of a simple expression that allows estimating the roughness correctly, after checking a too large deviation between the measured values and those calculated with the expression obtained from the reference article or the other references consulted.

- Establish minimum and maximum possible value for each variable under study, to give a practical outlet to the developed program.

- Find a correct expression that estimates the energy of the process according to the cutting parameters. In the expressions used in this work, working on the expressions of the torque and the cutting force has been proven their independence from these.

The sustainability index is obtained from the relationship, for each study variable, between the range of values defined for the cutting parameters and those initially considered. These initial data must be maintained in all cases under study. An improvement could allow the sustainability index to be reached regardless of the initial cut-off parameters considered.

This work opens a possible research line focussed on the universality of the model, applying it to other materials and machining operations. It has been verified that the modifications to be carried out on the algorithm are simple and that, as in the case of the drilling of composite materials, the limitation is found in the expressions and necessary data of the algorithm. 


\section{Acknowledgements}

The authors thank the Spanish Ministry of Economy and Competitiveness for funding received through the DPI2014-58007-R project, and the College of Industrial Engineers of UNED for its support through the 2017-IFC09 project.

\section{References}

Aguado, S.; Álvarez, R. \& Domingo, R. (2013). Model of efficient and sustainable improvements in a lean production system through processes of environmental innovation. Journal of Cleaner Production, Vol. 47, pp. 141-148, ISSN: 0959-6526, DOI: $10.1016 /$ j.jclepro.2012.11.048

Alvarez, R.; Domingo, R. \& Sebastian, M.A. (2011). The formation of saw toothed chip in a titanium alloy: Influence of constitutive models. Strojniški Vestnik - Journal of Mechanical Engineering, Vol. 57, No. 10, pp. 739-749, ISSN 0039-2480, DOI: 10.5545/sv-jme.2011.106

Calvo, L.M. \& Domingo, R. (2015). Influence of process operating parameters on CO2 emissions in continuous industrial plants. Journal of Cleaner Production, Vol. 96, pp. 253-262, ISSN: 0959-6526, DOI: 10.1016/j.jclepro.2014.05.016

Debnath, S.; Reddy, M.M. \& Yi, Q.S. (2014). Environmental friendly cutting fluids and cooling techniques in machining: a review. Journal of Cleaner Production, Vol. 83, pp. 33-47, ISSN: 0959-6526, DOI: 10.1016/j.jclepro.2014.07.071

Domingo, R. \& Aguado, S. (2015). Overall environmental equipment effectiveness as a metric of a lean and green manufacturing system. Sustainability, Vol. 7, No. 7, pp. 9031-9047, ISSN: 2071-1050, DOI: 10.3390/su7079031

Domingo, R.; de Agustina, B. \& Marín, M.M. (2018a). A multi-response optimization of thrust forces, torques, and the power of tapping operations by cooling air in reinforced and unreinforced polyamide PA66. Sustainability, Vol. 10, No. 3, pp. 889, ISSN: 2071-1050, DOI: 10.3390/su10030889

Domingo, R.; De Agustina, B. \& Marin, M.M. (2018b). Effect of cooling on the torque of tapping processes in polymer composites. DAAAM International Scientific Book 2017, B. Katalinic (Ed.), in press

Domingo, R.; García, M. \& Gómez, M.R. (2013b). Determination of energy during the dry drilling of PEEK GF30 considering the effect of torque. Procedia Engineering, Vol. 63, pp. 687-693, ISSN 1877-7058, DOI: 10.1016/j.proeng.2013.08.195

Domingo, R.; García, M.; Sánchez, A. \& Gómez, R. (2013a). A Sustainable evaluation of drilling parameters for PEEK-GF30. Materials, Vol. 6, pp. 5907-5922, ISNN 19961944, DOI: 10.3390/ma6125907

Domingo, R.; Marín, M.M.; Claver, J. \& Calvo, R. (2015). Selection of cutting inserts in dry machining for reducing energy consumption and $\mathrm{CO} 2$ emissions. Energies, Vol. 18, No. 11, pp. 13081-13095, ISSN: 1996-1073, DOI: 10.3390/en81112362

Hassine, H.; Barkallah, M.; Bellacicco, A.; Louati, J.; Riviere, A. \& Haddar, M. (2015). Multi objective optimization for sustainable manufacturing, application in turning. International Journal of Simulation Modelling, Vol. 14, No. 1, pp. 98-109, ISSN 17264529, DOI: 10.2507/IJSIMM14(1)9.292 
Toledano, C. \& Domingo, R.: A Sustainability Index for the Evaluation of Machini...

ISO 3685 (1993). Tool-life testing with single-point turning tools, International Organization for Standardization, Geneve.

Kalpakjian, S. \& Schmid, S. (2013). Manufacturing Engineering \& Technology (7th Edition), Pearson, ISBN 978-0133128741

Kralikova, R.; Rusko, M. \& Wessely, E. (2017). Ekolabeling as development facilitator of the environmentally oriented product policy. Proceedings of 28th DAAAM International Symposium on Intelligent Manufacturing and Automation, ISBN 978-390273411-2, ISSN 1726-9679, B. Katalinic (Ed.), pp.0124-0130, Published by DAAAM International, Vienna, Austria, DOI: 10.2507/28th.daaam.proceedings.016 Kumar, S. (2017). Review on optimization techniques used for determining machining conditions to get effective tool life and surface finish. DAAAM International Scientific Book 2017, B. Katalinic (Ed.), pp. 235-264, DAAAM International, ISBN: 978-3902734-12-9, Vienna

Majstorovic, V.; Medic, M. \& Bandic Glavas, M. (2016). Key elements analysis of projects' environmental impact assessment, Proceedings of the 27th DAAAM International Symposium on Intelligent Manufacturing and Automation, ISBN 978-3902734-08-2, ISSN 1726-9679, pp.0091-0094, B. Katalinic (Ed.), Published by DAAAM International, Vienna, Austria, DOI: 10.2507/27th.daaam.proceedings.013 Qehaja, N.; Doci, I.; Bruqi, M.; Abdullahu, F.; Jakupi, K. \& Zhujani, F. (2016). Mathematical modelling of surface roughness through machining parameters and machining time during the dry milling process, Proceedings of the 27th DAAAM International Symposium on Intelligent Manufacturing and Automation, ISBN 978-3902734-08-2, ISSN 1726-9679, pp.0187-0194, B. Katalinic (Ed.), Published by DAAAM International, Vienna, Austria, DOI: 10.2507/27th.daaam.proceedings.028 Rehar, T.; Ogrizek, B.; Leber, M.; Pisnik, A. \& Buchmeister, B. (2017). Product lifecycle forecasting using system's indicators. International Journal of Simulation Modelling, Vol. 16, No. 1, pp. 45-57, ISSN 1726-4529, DOI: 10.2507/IJSIMM16(1)4.366

Saric, T.; Simunovic, G.; Simunovic, K. \& Svalina, I. (2016). Estimation of machining time for CNC manufacturing using neural computing. International Journal of Simulation Modelling, Vol. 15, No. 4, pp. 663-675, ISSN 1726-4529, DOI: 10.2507/IJSIMM15(4)7.359

Tazehkandi, A.H.; Shabgard, M.; Kiani, G. \& Pilehvarian, F. (2016). Investigation of the influences of polycrystalline cubic boron nitride (PCBN) tool on the reduction of cutting fluid consumption and increase of machining parameters range in turning Inconel 783 using spray mode of cutting fluid with compressed air. Journal of Cleaner Production, Vol. 135, pp. 1637-1649, ISSN: 0959-6526, DOI: 10.1016/j.jclepro.2015.12.102

Tsai, S.B.; Xue, Y.Z.; Huang, P.Y.; Zhou, J.; Li, G.D.; Guo, W.F.; Lau, H. \& Shang, Z.W. (2015). Establishing a criteria system for green production. Proceedings of the Institution of Mechanical Engineers, Part B: Journal of Engineering Manufacture, Vol. 229, pp. 1395-1406, ISSN: 0954-4054, DOI: 10.1177/0954405414535923

Zuperl, U. \& Cus, F. (2015). Simulation and visual control of chip size for constant surface roughness. International Journal of Simulation Modelling, Vol. 14, No. 3, pp. 392-403, ISSN 1726-4529, DOI: 10.2507/IJSIMM14(3)2.282 